\title{
A mechanobiological perspective on cadherins and the actin-myosin cytoskeleton
}

\author{
Srikanth Budnar and Alpha S. Yap*
}

Address: Division of Molecular Cell Biology, Institute for Molecular Bioscience, The University of Queensland, St. Lucia, Brisbane, Australia 4072

* Corresponding author: Alpha S. Yap (a.yap@uq.edu.au)

Fl000Prime Reports 2013, 5:35 (doi:10.12703/P5-35)

This is an open-access article distributed under the terms of the Creative Commons Attribution-Non Commercial License (http://creativecommons.org/licenses/by-nc/3.0/legalcode), which permits unrestricted use, distribution, and reproduction in any medium, provided the original work is properly cited. You may not use this work for commercial purposes.

The electronic version of this article is the complete one and can be found at: http://fl000.com/prime/reports/b/5/35

\begin{abstract}
Classical cadherin receptors mediate morphogenetic cell-cell interactions within many tissues of the body. Their biological impact often entails cooperation between cadherin adhesion and the actin cytoskeleton, but how this may occur and - even more urgently - how this leads to morphogenetic outcomes are questions that remain poorly understood. Here, we suggest that the emerging field of cadherin mechanobiology provides a useful new perspective from which to revisit these issues. We propose that the actin cytoskeleton can be considered as an active agent that mediates how cadherin junctions resist, sense and transduce forces between cells.
\end{abstract}

\section{Introduction}

It has long been thought that classical cadherins function in close cooperation with the actin cytoskeleton. Early studies demonstrated that cadherin-dependent adhesion was compromised when actin integrity was disrupted [1] and genetic studies have shown that a variety of actin regulators participate in cadherin-dependent morphogenetic processes [2]. More recent analyses of cellular and molecular mechanisms indicate that cadherins interact, functionally and physically, with the cytoskeleton in at least three ways (reviewed in [3]). Firstly, cadherin molecular complexes can bind actin filaments through a number of mechanisms, mediated by proteins such as $\alpha$-catenin, myosin VI, vinculin and EPLIN. Secondly, cadherins regulate actin dynamics and filament organization at cell-cell junctions, both by physically recruiting proteins that can control actin dynamics (e.g. Arp2/3, formins, $\alpha$-actinin-4) and proteins that can influence crosslinking and filament organization (e.g. vinculin and $\alpha$-actinin-1). Thirdly, association with the actin cytoskeleton effectively allows cadherin junctions to couple to actomyosin contractile apparatuses. This reflects the ability of cadherins to recruit myosin II to the cortex [4], both through cortical signaling [5] and by assembling junctional F-actin networks [6]. Together, these cell-biological findings build a picture of cadherin-actin cooperativity that entails networks of dynamic molecular interactions and cortical signals.

We are thus making progress in defining molecular mechanisms that functionally couple cadherins to the junctional cytoskeleton. What is less clear is how specific mechanisms of cadherin-cytoskeletal cooperation contribute to the biological functions of cadherins. Here, we propose that the mechanobiology of cadherins can provide a framework to help map molecular mechanism onto biology. Cadherin junctions are mechanical agents and specific cytoskeletal mechanisms contribute to at least three aspects of their mechanobiology: (1) reinforcing surface adhesion to resist detachment forces; (2) coupling the force-generating apparatuses of neighbouring cells together; and (3) supporting mechanosensing and mechanotransduction at junctions. In this brief commentary, we illustrate how such models can assist in understanding the links between molecular mechanism and biological function.

\section{Adhesion: resisting detachment forces}

At a fundamental biophysical level, adhesion receptors allow cells to resist forces that would detach them from 
their surroundings. This requires that the bonds that form when cadherin ectodomains (extracellular domains) engage in adhesive (trans) interactions are able to resist detachment forces. One mechanism that supports adhesion at the cell surface is the lateral organization of cadherins into clusters, which promotes adhesion by increasing the avidity of adhesive bonds $[7,8]$. Lateral clustering is a common feature of cadherinbased cell-cell junctions, manifest as the spot adherens junctions described in Drosophila epithelia [9] and the puncta that have been observed in cultured mammalian epithelia [10,11].

Structural studies of isolated cadherin domains have demonstrated that cadherin ectodomains also undergo cis-interactions that can, in combination with adhesive trans-interactions, yield two-dimensional arrays that might explain the ability of cadherins to cluster [10]. Indeed, dynamic lateral clusters have been observed in cells expressing cadherin mutants that lack their cytoplasmic tails $[11,12]$. Yet in other studies clustering appeared to require an intact cytoplasmic domain [8]. Further, clustering of full-length cadherin was perturbed by drugs that disrupted actin integrity [11] or when either $\alpha$-catenin [13] or myosin II were depleted [14]. Together, these findings suggest that the actomyosin cytoskeleton and its coupling to cadherin cooperate with the interactions of the ectodomain to support clustering.

How might this cooperation occur? A key lies in the observation that clusters formed by tail-less cadherin mutants are very small (diffraction-limited) and transient (lifetime < $2 \mathrm{sec}$ ) structures, whose dynamic nature may reflect the binding-unbinding kinetics of ectodomain interactions [11]. These were stabilized, in an actindependent manner, when the cadherin mutants were fused to the F-actin-binding domains of either $\alpha$-catenin or of utrophin [11]. Thus, actin binding can stabilize the intrinsically unstable kinetics of ectodomain interactions. This stabilizing influence of cortical actin may also involve myosin, as inhibiting myosin II or its upstream regulatory signals reduced the junctional stability of E-cadherin $[5,15]$. This implies that interaction with actomyosin, rather than simply with cortical F-actin, can stabilize cadherin, as it promotes clustering [14]. One possible model is that cortical F-actin networks serve as diffusional traps for surface cadherin, thereby promoting rebinding of ectodomain interactions. Myosin could then contribute through its ability to cross-link and potentially organize actin filament networks [16,17].

\section{Coupling cortices together}

What then is the source of those forces that cadherin adhesion resists? Here, an important conceptual advance has come from the realization that force often derives from actomyosin networks in the cells that make up the junctions themselves [18-20]. Thus, cadherins at a junction are subject to contractile forces from neighbouring cells (transmitted presumably through transinteractions with neighbouring cadherins) and also from within their own host cell [21]. This is strikingly evident in studies of epithelial morphogenesis, where apical contractile networks of actin and myosin exert forces on cell-cell junctions to drive folding of tissues and cell intercalation [22-24]. Such contractility is often pulsatile, each contraction producing local deformation of adherens junctions, consistent with the transmission of force to the junctions [22]. Further, at the molecular level, the use of cadherin fusion proteins bearing tension-sensitive FRET biosensors has demonstrated that both E-cadherin and VE cadherin are under tension at junctions in epithelial and endothelial cells, respectively $[25,26]$. Molecular-level tension on E-cadherin was relieved by disruption of actin and myosin or when $\alpha$-catenin was depleted, implying that it reflected actomyosin contractility that was coupled to the cadherin [26]. A line-tension within junctions can also be demonstrated at a mesoscopic level, when those junctions are cut using high-powered lasers, resulting in instantaneous recoil of the residual junctions $[5,13]$. This junctional tension also depends on the dynamic assembly of an actomyosin network [6] and cortical signals that activate myosin [3].

Coupling of cadherins to intracellular contractility provides several new ways to think about the morphogenetic influence of cadherins. First, while actomyosin contributes the forces needed for events such as tissue invagination, effective morphogenesis also requires that the contractile networks be physically coupled to adherens junctions [27]. Here, cadherin junctions can be considered as resistance elements that are essential for contractility to induce the cell shape changes needed for morphogenesis. Second, cadherin adhesions link the contractile apparatuses of individual cells together, thereby effectively generating tissue-level contractile networks $[24,28,29]$. Indeed, supracellular patterns of contractile tension that become polarized during development require cadherin junctions for their organization [28]. Third, coupling of cadherin to contractility can serve as a regulated step during morphogenesis. Active actomyosin networks were recently identified in C. elegans and Drosophila embryonic cells even before they began to undergo cell intercalation during morphogenesis [30]. However, the onset of morphogenesis coincided with their coupling to adherens junctions, which were necessary for morphogenesis to proceed. This suggests that engagement of the actomyosin network to 
cadherin adhesions can constitute a developmentally regulated step in converting actomyosin activity into biologically effective force.

The physical coupling of cadherin to actomyosin probably occurs by binding of the cadherin to actin filaments, rather than to myosin II itself. As noted above, many actin-binding proteins have now been described that can interact with cadherins, but the biological reasons for this diversity remain obscure. One possible explanation is that different actin-binding proteins contribute in a context-dependent fashion. For example, in Drosophila embryos the cortical protein Canoe (afadin in mammals) can bind to DE-cadherin and couples actomyosin networks to junctions [31]. During the process of mesoderm invagination, Canoe appeared to be uniformly localized at junctions [31]. However, in another morphogenetic event, germband extension, Canoe was planar polarized, accumulating only in a subset of adherens junctions to which it selectively coupled actomyosin networks [32]. Some connections between junctions and actomyosin did persist when Canoe was depleted, suggesting that the coupling of actomyosin to cadherins may not involve a single mechanism. Perhaps basal connectivity is established by proteins such as $\alpha$-catenin [13], which are ubiquitously associated with the cadherin-catenin complex. Other proteins, such as Canoe, may then be layered upon this basal mechanism to bias actomyosin coupling to specific subsets of junctions.

\section{Mechanosensing and mechanotransduction}

Until now, we have treated cadherin adhesion largely as a passive resistance element in cooperation with actomyosin. The capacity for cadherin adhesions to regulate cytoskeletal dynamics $[6,33]$ and cell signaling $[5,34,35]$ also raises the possibility that cadherin may serve as an active agent. In particular, there is increasing evidence that cadherin junctions exist in a homeostatic relationship with the forces that act upon them. This might be inferred from the observation that cadherin junctions must resist the contractile forces that drive morphogenesis for development itself to proceed [27]. The notion was also prompted by the observation that in cultured epithelial cells, E-cadherin accumulates and is stabilized at the zonula adherens in a myosin-dependent fashion $[5,14,36]$. It was substantiated by the demonstration that junctional size increased proportionally to the tugging forces exerted upon them [37]. Further, the cortical stiffness of cadherin adhesions also increases in response to forces, and in an actin- and myosindependent fashion [38]. Together, these observations imply that, by some means, cadherin junctions respond to the forces that act upon them. An analogous process (adhesive strengthening) is thought to regulate the size of integrin adhesions $[39,40]$.

These homeostatic responses might be conceived as involving two inter-related processes: the ability of cadherins and their associated proteins to sense the forces that act upon them (mechanosensing); and then their ability to elicit cellular responses proportional to those mechanical stimuli (mechanotransduction). One way that force can be sensed is if the conformation of the protein is altered, and consequently its biochemical function, upon the application of force. For example, stretching of the integrin-associated protein talin can influence its ability to bind its partner, vinculin [41]. For cadherin junctions, proteins with actin-binding capacity are especially relevant, as an intrinsic ability to bind F-actin would place them well to experience force. An attractive candidate is $\alpha$-catenin itself, which can directly bind F-actin and the cadherin- $\beta$-catenin complex. $\alpha$-catenin can also recruit a range of other proteins, such as the F-actin binding protein vinculin [42,43]. However, the ability of $\alpha$-catenin to recruit vinculin to junctions depends on myosin activity [44], suggesting that it might be influenced by tension. This notion is reinforced by evidence that the $\mathrm{N}$ - and C-termini of $\alpha$-catenin can bind to one another [44], and thereby inhibit vinculin binding [45]. Thus, it has been attractive to postulate that tension alters the conformation of $\alpha$-catenin to influence protein binding, as it does for talin. Support for this idea has come from the observation that an epitope located centrally in the $\alpha$-catenin molecule was only detected when myosin was active [44]. It should be emphasized, though, that this hypothesis has yet to be thoroughly addressed, either in cells or with purified proteins. Nonetheless, this remains very attractive, since tension-sensitive conformational change is a very rapid way for proteins to respond to force.

Force-sensitive changes in actin-binding proteins also provide a direct way in which force-sensing can be coupled to a cytoskeletal response. Here, it is germane to note that vinculin is necessary for the cortical stiffening that occurs when cadherin adhesions are mechanically stimulated [38]. Vinculin might serve as part of the cellular response to force on cadherin junctions, as it can influence the cytoskeleton directly, by cross-linking F-actin, and by recruiting other actin-regulatory proteins that can influence filament dynamics and/or organization [46]. There are also other proteins found at cadherin junctions that have the potential to be force-sensitive, including myosin VI [47] and myosin II $[48,49]$. Of course, this by no means exhausts the range of mechanotransduction mechanisms that may be 
available when cadherin adhesions are exposed to force. Cadherins can regulate a range of cortical signals, including Rho family GTPases and Src family kinases $[34,50]$, which can in turn influence the cytoskeleton. It will be exciting to see if these, too, are altered when cadherins are stimulated by force.

\section{Future directions}

Classical cadherins support many biologies: these range from tissue cohesion, through morphogenesis, to the control of cell proliferation. Their contribution to these various processes arises not solely through their ability to support surface adhesion but also in cooperation with intracellular processes. But there is a challenge in understanding how molecular mechanism maps to biology. One approach to parsing this problem is to identify the intermediate levels of analysis. We suggest that understanding how cadherins serve as mechanically active agents provides one such intermediate level, which can illuminate how cooperation with the actin cytoskeleton influences the biological impacts of cadherins. Insofar as mechanical factors are increasingly implicated in many other biologies, including proliferative control [51] and receptor-ligand recognition [52], it will be interesting to see how broadly useful a mechanobiological perspective will be.

\section{Disclosures}

The authors declare that they have no disclosures.

\section{Acknowledgements}

We thank our lab colleagues for many fruitful discussions. Our work is supported by the National Health and Medical Research Council of Australia (APP1037320, APP1044041).

\section{References}

I. Jaffe SH, Friedlander DR, Matsuzaki F, Crossin KL, Cunningham BA, Edelman GM: Differential effects of the cytoplasmic domains of cell adhesion molecules on cell aggregation and sorting-out. Proceedings of the National Academy of Sciences of the United States of America 1990, 87(9):3589-3593.

\section{FlOOOPrime
RECOMMENDED}

2. Baum B, Perrimon N: Spatial control of the actin cytoskeleton in Drosophila epithelial cells. Nat Cell Biol 200I, 3(10):883-890.

\section{FlOOPrime}

\section{RECOMMENDED}

3. Ratheesh A, Yap AS: A bigger picture: classical cadherins and the dynamic actin cytoskeleton. Nature reviews Molecular cell biology 2012, I3:673-679.

4. Shewan AM, Maddugoda M, Kraemer A, Stehbens SJ, Verma S, Kovacs EM, Yap AS: Myosin 2 Is a Key Rho Kinase Target Necessary for the Local Concentration of E-Cadherin at CellCell Contacts. Mol Biol Cell 2005, 16:453 I-4532.

5. Ratheesh A, Gomez GA, Priya R, Verma S, Kovacs EM, Jiang K, Brown NH, Akhmanova A, Stehbens SJ, Yap AS: Centralspindlin and alpha-catenin regulate $\mathrm{Rho}$ signalling at the epithelial zonula adherens. Nat Cell Biol 2012, I4:818-828.

\section{FlOOOPrime}

6. Verma S, Han SP, Michael M, Gomez GA, Yang Z, Teasdale RD, Ratheesh A, Kovacs EM, Ali RG, Yap AS: A WAVE2-Arp2/3 actin nucleator apparatus supports junctional tension at the epithelial zonula adherens. Mol Biol Cell 20I2, 23:460I-46I0.

7. Angres B, Barth A, Nelson WJ: Mechanism for transition from initial to stable cell-cell adhesion: kinetic analysis of E-cadherin-mediated adhesion using a quantitative adhesion assay. J Cell Biology 1996, 134:549-557.

8. Yap AS, Brieher WM, Pruschy M, Gumbiner BM: Lateral clustering of the adhesive ectodomain: a fundamental determinant of cadherin function. Current Biology 1997, 7:308-315.

9. Tepass $U$, Hartenstein $\mathrm{V}$ : The development of cellular junctions in the Drosophila embryo. Dev Biol 1994, I6 I(2):563-596.

\section{FIOOOPrime}

\section{RECOMMENDED}

10. Harrison OJ, Jin X, Hong S, Bahna F, Ahlsen G, Brasch J, Wu Y, Vendome J, Felsovalyi K, Hampton CM, Troyanovsky RB, Ben-Shaul A, Frank J, Troyanovsky SM, Shapiro L, Honig B: The extracellular architecture of adherens junctions revealed by crystal structures of type I cadherins. Structure 20I I, I 9(2):244-256.

\section{FlOOOPrime}

\section{RECOMMENDED}

II. Hong S, Troyanovsky RB, Troyanovsky SM: Binding to F-actin guides cadherin cluster assembly, stability, and movement. The Journal of cell biology 2013, 20I(I):I31-143.

\section{FlOOOPrime \\ RECOMMENDED}

12. Hong S, Troyanovsky RB, Troyanovsky SM: Cadherin exits the junction by switching its adhesive bond. The Journal of cell biology 201 I, I92(6): 1073-1083.

FlOOOPrime RECOMMENDED

13. Cavey M, Rauzi M, Lenne PF, Lecuit T: A two-tiered mechanism for stabilization and immobilization of E-cadherin. Nature 2008, 453(7|96):75I-756.

FlOOOPrime RECOMMENDED

14. Smutny M, Cox HL, Leerberg JM, Kovacs EM, Conti MA, Ferguson C, Hamilton NA, Parton RG, Adelstein RS, Yap AS: Myosin II isoforms identify distinct functional modules that support integrity of the epithelial zonula adherens. Nat Cell Biol 2010, I2(7):696-702.

FlOOOPrime RECOMMENDED

15. Priya R, Yap AS, Gomez GA: E-cadherin supports steady-state Rho signaling at the epithelial zonula adherens. Differentiation; research in biological diversity 2013.

16. Gowrishankar K, Ghosh S, Saha S, C R, Mayor S, Rao M: Active remodeling of cortical actin regulates spatiotemporal organization of cell surface molecules. Cell 2012, I49(6): I353-I367.

\section{FlOOOPrime}

RECOMMENDED

17. West-Foyle H, Robinson DN: Cytokinesis mechanics and mechanosensing. Cytoskeleton (Hoboken) 2012, 69(10):700-709.

18. Bertet C, Sulak L, Lecuit T: Myosin-dependent junction remodelling controls planar cell intercalation and axis elongation. Nature 2004, 429:667-67I.

FlOOOPrime RECOMMENDED

19. Costa M, Raich W, Agbunag C, Leung B, Hardin J, Priess JR: A putative catenin-cadherin system mediates morphogenesis 
of the Caenorhabditis elegans embryo. J Cell Biol 1998, I 4 I:297-308

\section{FlOOOPrime

RECOMMENDED

20. Maitre JL, Berthoumieux H, Krens SF, Salbreux G, Julicher F, Paluch E, Heisenberg CP: Adhesion functions in cell sorting by mechanically coupling the cortices of adhering cells. Science 20I2, 338(6I04):253-256.

\section{FlOOOPrime \\ RECOMMENDED}

21. Kwiatkowski AV, Maiden SL, Pokutta S, Choi HJ, Benjamin JM, Lynch AM, Nelson WJ, Weis WI, Hardin J: In vitro and in vivo reconstitution of the cadherin-catenin-actin complex from Caenorhabditis elegans. Proceedings of the National Academy of Sciences of the United States of America 2010, 107(33): I459I-I 4596.

\section{FlOOOPRime}

22. Martin AC, Kaschube M, Wieschaus EF: Pulsed contractions of an actin-myosin network drive apical constriction. Nature 2009, 457(7228):495-499.

\section{FlOOOPrime}

\section{RECOMMENDED}

23. Fernandez-Gonzalez R, Zallen JA: Oscillatory behaviors and hierarchical assembly of contractile structures in intercalating cells. Phys Biol 20I I, 8(4):045005.

\section{FlOOOPrime \\ RECOMMENDED}

24. Rauzi M, Lenne PF, Lecuit T: Planar polarized actomyosin contractile flows control epithelial junction remodelling. Nature 2010, 468(7327): III0-III4.

\section{FlOOOPrime}

25. Conway DE, Breckenridge MT, Hinde E, Gratton E, Chen CS, Schwartz MA: Fluid Shear Stress on Endothelial Cells Modulates Mechanical Tension across VE-Cadherin and PECAM-I. Current biology : CB 2013, 23(II): 1024-1030.

\section{FlOOOPrime}

\section{RECOMMENDED}

26. Borghi N, Sorokina M, Shcherbakova OG, Weis WI, Pruitt BL, Nelson WJ, Dunn AR: E-cadherin is under constitutive actomyosin-generated tension that is increased at cell-cell contacts upon externally applied stretch. Proceedings of the National Academy of Sciences of the United States of America 2012, 109(3I): I 2568-12573.

\section{FlOOOPrime} RECOMMENDED

27. Dawes-Hoang RE, Parmar KM, Christiansen AE, Phelps CB, Brand AH, Wieschaus EF: folded gastrulation, cell shape change and the control of myosin localization. Development 2005, I32(I8): $4|65-4| 78$.

\section{FlOOOPrime}

28. Martin AC Gelbart M, Fernandez-Gonzalez $R$, Kaschube $M$, Wieschaus E: Integration of contractile forces during tissue invagination. J Cell Biol 2010, 188:735-749.

\section{FlOOOPrime} RECOMMENDED

29. Roper K: Supracellular actomyosin assemblies during development. Bioarchitecture 2013, 3(2).

\section{FlOOOPrime} RECOMMENDED

30. Roh-Johnson M, Shemer G, Higgins $C D$, McClellan JH, Werts $A D$, Tulu US, Gao L, Betzig E, Kiehart DP, Goldstein B: Triggering a cell shape change by exploiting preexisting actomyosin contractions. Science 2012, 335(6073): 1232-1235.

\section{FIOOOPrime}

3I. Sawyer JK, Harris NJ, Slep KC, Gaul U, Peifer M: The Drosophila afadin homologue Canoe regulates linkage of the actin cytoskeleton to adherens junctions during apical constriction. The Journal of cell biology 2009, 186(I):57-73.

\section{FlOOOPrime}

32. Sawyer JK, Choi W, Jung KC, He L, Harris NJ, Peifer M: A contractile actomyosin network linked to adherens junctions by Canoe/afadin helps drive convergent extension. Mol Biol Cell $201 \mathrm{I}$.

\section{FlOOOPrime}

RECOMMENDED

33. Tang VW, Brieher WM: alpha-Actinin-4/FSGSI is required for Arp2/3-dependent actin assembly at the adherens junction. The Journal of cell biology 2012, I96(I):II5-130.

\section{FlOOOPrime
RECOMMENDED}

34. Yamada S, Nelson W]: Localized zones of Rho and Rac activities drive initiation and expansion of epithelial cell-cell adhesion. The Journal of cell biology 2007, 178(3):5 I7-527.

\section{FlOOOPrime}

35. Wildenberg GA, Dohn MR, Carnahan RH, Davis MA, Lobdell NA Settleman J, Reynolds AB: pl20-catenin and pl90RhoGAP regulate cell-cell adhesion by coordinating antagonism between Rac and Rho. Cell 2006, I 27(5): 1027-1039.

\section{FlOOOPrime \\ RECOMMENDED}

36. Miyake $\mathrm{Y}$, Inoue $\mathrm{N}$, Nishimura $\mathrm{K}$, Kinoshita $\mathrm{N}$, Hosoya $\mathrm{H}$, Yonemura S: Actomyosin tension is required for correct recruitment of adherens junction components and zonula occludens formation. Exp Cell Res 2006, 3 I2(9):1637-1650.

\section{FlOOOPrime \\ RECOMMENDED}

37. Liu Z, Tan JL, Cohen DM, Yang MT, Sniadecki NJ, Ruiz SA, Nelson CM, Chen CS: Mechanical tugging force regulates the size of cell-cell junctions. Proceedings of the National Academy of Sciences of the United States of America 2010, 107:9944-9949.

\section{FlOOOPrime
RECOMMENDED}

38. le Duc Q, Shi Q, Blonk I, Sonnenberg A, Wang N, Leckband D, de Rooij J: Vinculin potentiates E-cadherin mechanosensing and is recruited to actin-anchored sites within adherens junctions in a myosin II-dependent manner. The Journal of cell biology 2010, I89(7): I I07-III5.

\section{FlOOOPrime
RECOMMENDED}

39. Balaban NQ, Schwarz US, Riveline D, Goichberg P, Tzur G, Sabanay I, Mahalu D, Safran S, Bershadsky A, Addadi L, Geiger B: Force and focal adhesion assembly: a close relationship studied using elastic micropatterned substrates. Nat Cell Biol 200I, 3(5): 466-472.

\section{FlOOOPrime}

RECOMMENDED

40. Riveline D, Zamir E, Balaban NQ, Schwarz US, Ishizaki T, Narumiya S, Kam Z, Geiger B, Bershadsky AD: Focal contacts as mechanosensors: externally applied local mechanical force induces growth of focal contacts by an mDial-dependent and 
ROCK-independent mechanism. The Journal of cell biology 200I, I53(6): I I75-I I 86.

FIOOOPrime

41. del Rio A, Perez-Jimenez R, Liu R, Roca-Cusachs P, Fernandez JM, Sheetz MP: Stretching single talin rod molecules activates vinculin binding. Science 2009, 323(59|4):638-64I.

\section{FlOOOPrime \\ RECOMMENDED}

42. Watabe-Uchida $M$, Uchida N, Imamura $Y$, Nagafuchi A, Fujimoto $K$, Uemura T, Vermeulen S, van Roy F, Adamson ED, Takeichi M: alphaCatenin-vinculin interaction functions to organize the apical junctional complex in epithelial cells. The Journal of cell biology 1998, I42(3):847-857.

\section{FlOOOPrime}

43. Huveneers S, Oldenburg J, Spanjaard E, van der Krogt G, Grigoriev I, Akhmanova A, Rehmann $H$, de Rooij J: Vinculin associates with endothelial VE-cadherin junctions to control forcedependent remodeling. The Journal of cell biology 20 I 2, I 96(5):64I-652.

\section{FlOOOPrime} RECOMMENDED

44. Yonemura S, Wada $\mathrm{Y}$, Watanabe $\mathrm{T}$, Nagafuchi A, Shibata M: alphaCatenin as a tension transducer that induces adherens junction development. Nat Cell Biol 2010, I2:533-542.

\section{FlOOOPrime}

\section{RECOMMENDED}

45. Choi HJ, Pokutta S, Cadwell GW, Bobkov AA, Bankston LA, Liddington RC, Weis Wl: alphaE-catenin is an autoinhibited molecule that coactivates vinculin. Proceedings of the National Academy of Sciences of the United States of America 20 I2, 109:8576-858I.
46. Leerberg JM, Yap AS: Vinculin, cadherin mechanotransduction and homeostasis of cell-cell junctions. Protoplasma 2012.

47. Maddugoda MP, Crampton MS, Shewan AM, Yap AS: Myosin VI and vinculin cooperate during the morphogenesis of cadherin cell-cell contacts in mammalian epithelial cells. J Cell Biol 2007, I78:529-540.

\section{FlOOOPrime}

\section{RECOMMENDED}

48. Altman D, Sweeney HL, Spudich JA: The mechanism of Myosin VI translocation and its load-induced anchoring. Cell 2004, I I 6:737-749.

FlOOOPrime
RECOMMENDED

49. De la Cruz EM, Ostap EM: Relating biochemistry and function in the myosin superfamily. Curr Op Cell Biol 2004, 16:61-67.

\section{FlOOOPrime} RECOMMENDED

50. McLachlan RW, Kraemer A, Helwani FM, Kovacs EM, Yap AS: E-cadherin adhesion activates c-Src signaling at cell-cell contacts. Mol Biol Cell 2007, I8:32|4-3223.

5I. Dupont S, Morsut L, Aragona M, Enzo E, Giulitti S, Cordenonsi M, Zanconato F, Le Digabel J, Forcato M, Bicciato S, Elvassore N, Piccolo S: Role of YAP/TAZ in mechanotransduction. Nature 20II, 474(7350): I79-183.

\section{FlOOOPrime}

RECOMMENDED

52. Natkanski E, Lee WY, Mistry B, Casal A, Molloy JE, Tolar P: B cells use mechanical energy to discriminate antigen affinities. Science 2013, 340(6I40): 1587-1590.

\section{FlOOOPrime}

